\title{
Influence of Heat Exposure on Serum Lipid and Lipoprotein Cholesterol in Young Male Subjects
}

\author{
Hiromi YAMAMOTO*, Kui-Cheng ZHENG and Makoto ARIIZUMI \\ Department of Preventive Medicine, Faculty of Medicine, University of the Ryukyus, 207 Uehara, Nishihara, \\ Okinawa 903-0215, Japan
}

Received March 20, 2002 and accepted August 29, 2002

\begin{abstract}
The aims of the present study were to determine the effects of passive heat exposure on serum lipid concentrations in healthy young Japanese males and to analyze the relationship between subjects' physical characteristics and the extent of change in serum lipid concentrations. Thirteen subjects with mean ages of $22.6 \pm 1.0$ (mean $\pm \mathrm{SE}$ ) years were each exposed to control temperature (Tc: $25.2 \pm 0.0^{\circ} \mathrm{C}$ ), moderate ( $\mathrm{Tm}: 35.5 \pm 0.2^{\circ} \mathrm{C}$ ) and high temperature $\left(\mathrm{Th}: 39.8 \pm 0.1^{\circ} \mathrm{C}\right.$ ), at a relative humidity of $60.3 \pm 1.2 \%$ for one hour. Each exposure was carried out on a different day in random sequence. Blood samples were collected just before, during and after the exposure, and serum lipid concentrations were analyzed. In the Tc condition, the concentrations of total cholesterol (TC), HDL-cholesterol (HDL-C), LDL-cholesterol (LDL-C), triglyceride (TG), and free fatty acid (FFA) did not change significantly. In the Tm condition, HDL-C increased significantly after the exposure and FFA increased during and after exposure. While in the Th condition, TC and TG decreased significantly during and after exposure, and LDL-C decreased during exposure. The correlation between changes in serum lipid concentrations and physical characteristics was analyzed if lipid concentrations changed significantly during or after exposure, but no significant correlation was found. The results indicate passive heat exposure has an effect on serum lipid concentrations which is independent of physical characteristics.
\end{abstract}

Key words: Heat exposure, Male subjects, Serum lipid concentrations, Physical characteristics

\section{Introduction}

During exercise sweating occurs as the body temperature rises, and the circulating plasma volume subsequently decreases. These physiological reactions may also occur when exposed to heat while keeping the body at rest. Physical exercise has been reported to cause acute reduction in serum total cholesterol (TC), low-density lipoprotein cholesterol (LDL-C) and triglyceride (TG) while it increases high-density lipoprotein cholesterol (HDL-C) and free fatty acid (FFA) $)^{1-5)}$. Due to the scarcity of reports it is not known exactly whether the rising body temperature caused by wholly heat exposure accounts for the changes in serum lipids. Results of some studies have shown that serum triglyceride

*To whom correspondence should be addressed. and cholesterol concentrations in people working outdoors in summer were significantly reduced, implying an inhibiting effect of heat on lipid synthesis ${ }^{6,7)}$. The effect of heat on serum lipid concentrations, however, is obscured due to the existence of confounding factors such as the discrepancies in heat exposure and the influence of physical or mental load on the subjects. William et al. ${ }^{8)}$ reported that experimental exposure of eight students aged 18 to 25 at $41^{\circ} \mathrm{C}$ for six hours caused serum cholesterol concentrations to increase 14 percent without a change in the lipoprotein cholesterol fractions. However, the exact change in lipid concentrations could not be evaluated because the variables were not adjusted for the degree of dehydration caused by sweating.

The present study is aimed at investigating the effects of heat exposure, without physical load, on lipoprotein 
cholesterols, triglyceride and free fatty acid in healthy young Japanese males. It is also aimed at comparing the effects of heat exposure with those of exercise on changes in serum lipid concentrations as published in other reports. The correlation between changes in serum lipid concentrations and physical characteristics is also analyzed.

\section{Materials and Methods}

\section{Subjects}

Due to the possibility that female subjects could not tolerate the heat exposure ${ }^{8)}$, we recruited healthy male Japanese university students. They were informed of the purpose of the study and their individual written informed consents were obtained. The study was carried out in accordance with the Declaration of Helsinki.

Sixteen candidates were medically screened prior to the study. Preliminary screening included physical examination and measurements of resting pulse rate and blood pressure. Blood samples were taken to evaluate serum protein, lipids, sugar, hepatic enzymes, blood urea nitrogen, and blood cell count. Urine protein and sugar were also measured. Thirteen male subjects aged $22.6 \pm 1.0$ (mean \pm SE) years who met the clinical standard participated in the study.

Body mass index (BMI), body surface area (BSA), waist to hip ratio $(\mathrm{W} / \mathrm{H})$ and percentage body fat $(\mathrm{BF})$ of the subjects were calculated $^{9-11)}$. The index of visceral fat deposition, determined as the ratio of the maximum thickness of the pre-peritoneal fat $\left(\mathrm{P}_{\max }\right)$ to the minimum thickness of the subcutaneous fat $\left(\mathrm{S}_{\min }\right)$ of the subjects $\left(\mathrm{P}_{\max } / \mathrm{S}_{\min }\right)$, was also determined prior to the experiment by using ultrasonography ${ }^{12)}$. In order to investigate the relationship between these physical factors and changes in serum lipid concentrations, no limitations were set on physical characteristics of the subjects. Their physical characteristics are summarized in Table 1.

\section{Procedures}

The subjects were not allowed to eat or drink anything $12 \mathrm{hrs}$ prior to and during the experiment. All the subjects wore light T-shirts, shorts and trousers. After verifying that they had no physical complaints, they were asked to empty their bladder before the experiment started. Each subject was exposed çw all 3 experimental conditions in random sequence, with one exposure per subject each day on three different days at least one week apart.

The subjects sat in the experimental room with an ambient temperature of $25.3 \pm 0.1^{\circ} \mathrm{C}$ for $30 \mathrm{~min}$, then entered a climatic chamber for $60 \mathrm{~min}$, and returned to the experimental
Table 1. Physical characteristics of subjects

\begin{tabular}{lr}
\hline Age $(\mathrm{yr})$ & $22.6 \pm 1.0$ \\
$\mathrm{BMI}^{\mathrm{a}}\left(\mathrm{kg} / \mathrm{m}^{2}\right)$ & $22.5 \pm 0.7$ \\
$\mathrm{BSA}^{\mathrm{b}}\left(\mathrm{m}^{2}\right)$ & $1.8 \pm 0.0$ \\
$\mathrm{~W}^{\mathrm{c}} \mathrm{H}^{\mathrm{c}}$ & $0.8 \pm 0.0$ \\
$\mathrm{BF}^{\mathrm{d}}(\%)$ & $27.0 \pm 1.6$ \\
$\mathrm{P}_{\text {max }} / \mathrm{S}_{\text {min }}{ }^{\mathrm{e}}$ & $0.7 \pm 0.1$ \\
\hline
\end{tabular}

a: body mass index, b: body surface area, c: the ratio of waist to hip circumference, $d$ : percent body fat, e: the ratio of the maximum thickness of preperitoneal fat to minimum thickness of subcutaneous fat. Values are expressed as mean $\pm \mathrm{SE}$.

room where they sat again for another $30 \mathrm{~min}$. They were kept seated on a chair during the experiment except when they moved between rooms. The conditions in the climatic chamber were as follows: 1$)$ control temperature (Tc): 25.2 $\left.\pm 0.0^{\circ} \mathrm{C}, 2\right)$ moderate temperature (Tm): $35.5 \pm 0.2^{\circ} \mathrm{C}$ and 3) high temperature (Th): $39.8 \pm 0.1^{\circ} \mathrm{C}$. Mean relative humidity during the sessions of the experiment was $60.3 \pm$ $1.2 \%$. Environmental heat stress was evaluated with the wet bulb globe temperature (WBGT) Index which is derived from the formula ${ }^{13)}$

$$
\begin{aligned}
& \text { WBGT }\left({ }^{\circ} \mathrm{C}\right)=0.7 \mathrm{NWB}+0.3 \mathrm{GT} \\
& \mathrm{NWB}=\text { natural wet-bulb temperature } \\
& \mathrm{GT}=\text { globe temperature }
\end{aligned}
$$

Vital signs (pulse rate, blood pressure and sublingual temperature) were measured just before entering the climatic chamber, every ten minutes in the climatic chamber and 30 min after return to the experimental room. The mean arterial blood pressure (MAP) was calculated ${ }^{14)}$. About $10 \mathrm{ml}$ of blood samples were obtained through an indwelling needle in the antecubital vein just before exposure, after $30 \mathrm{~min}$ and $60 \mathrm{~min}$ of exposure, and $30 \mathrm{~min}$ after exposure (Fig. 1).

Hemoglobin concentration and hematocrit were determined in order to estimate the relative changes in plasma volume individually ${ }^{15)}$, and the statistical difference was not analyzed (Table 2). TC, LDL-C (except for VLDL-C), HDL$\mathrm{C}$, TG and FFA were measured, and their concentrations were adjusted for the estimated plasma volume changes.

\section{Analysis}

ANOVA was used to analyze the differences between the mean values of the three different conditions. The differences between the mean values before the exposure and during and after the exposure were analyzed by using Dunnett test. TG concentrations in the Tm condition were not normally 


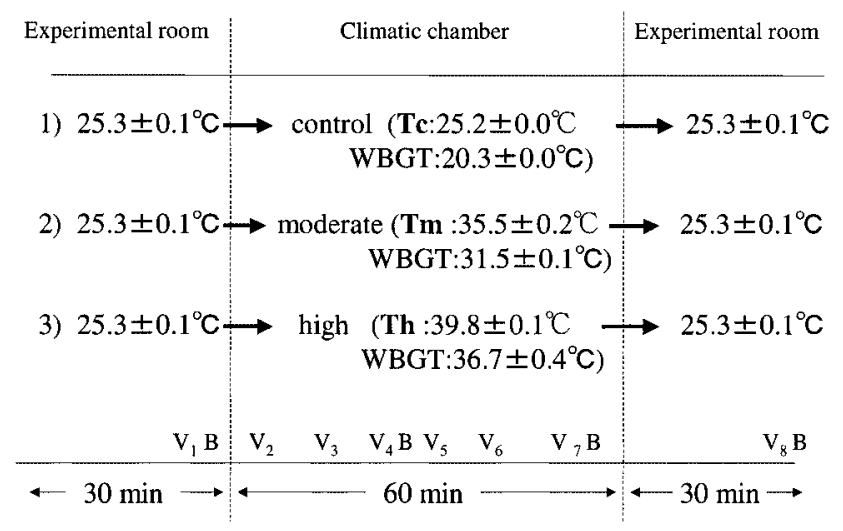

Fig. 1. Protocol of the experiment

The subjects were exposed to 1),2) and 3) condition respectively on three separate days at least one week apart from each other. The blood samples were collected at before exposure, $30 \mathrm{~min}, 60 \mathrm{~min}$ and after exposure. Vital signs were measured every $10 \mathrm{~min}\left(\mathrm{~V}_{1} \sim \mathrm{V}_{7}\right)$ and $30 \mathrm{~min}$ after exposure $\left(\mathrm{V}_{8}\right)$. V: Measure the vital sign, B: blood sampling. WBGT: wet bulb globe temperature.

Table 2. Estimated percent change in plasma volume

\begin{tabular}{lcrr}
\hline & $30 \mathrm{~min}$ & $60 \mathrm{~min}$ & \multicolumn{1}{c}{ After } \\
\hline $\mathrm{Tc}$ & $-0.4 \pm 0.3$ & $-1.4 \pm 0.7$ & $0.2 \pm 0.3$ \\
$\mathrm{Tm}$ & $-0.1 \pm 0.7$ & $-2.7 \pm 0.7$ & $1.1 \pm 0.6$ \\
$\mathrm{Th}$ & $-3.3 \pm 0.6$ & $-7.8 \pm 0.6$ & $-2.3 \pm 0.8$ \\
\hline
\end{tabular}

Values are expressed as means $\pm \mathrm{SE}$.

distributed and they were further analyzed by using KruskalWallis ${ }^{16,17)}$. We investigated whether the subjects with higher body mass showed higher lipid concentration change during heat exposure. If the serum lipid concentration of the subjects changed significantly during and after exposure, as compared to pre-exposure concentration, Pearson's correlation coefficients were calculated for the differences in serum lipid concentrations and the several physical characteristics (BMI, $\mathrm{BSA}, \mathrm{W} / \mathrm{H}, \mathrm{BF}$ and $\mathrm{P}_{\max } / \mathrm{S}_{\min }$ ) of the subjects. All data were expressed as mean $\pm \mathrm{SE}$, and $\mathrm{p}$ values less than 0.05 were regarded as statistically significant.

\section{Result}

All the subjects completed the study without any difficulty and showed no abnormal symptoms during the experiment. WBGT were $20.3 \pm 0.0^{\circ} \mathrm{C}, 31.5 \pm 0.1^{\circ} \mathrm{C}$ and $36.7 \pm 0.4^{\circ} \mathrm{C}$ in the Tc, Tm and Th conditions (Fig. 1).

As shown in Fig. 2, MAP did not change significantly during and after the exposure in the three experimental

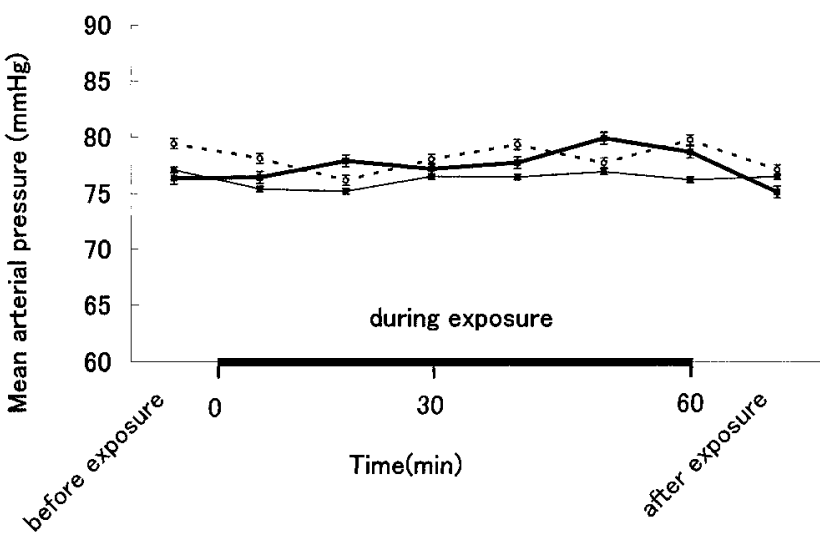

Fig. 2. Mean arterial blood pressure changes of Tc $(O), \mathbf{T m}($ and Th ( $\square)$

Values are means \pm SE.

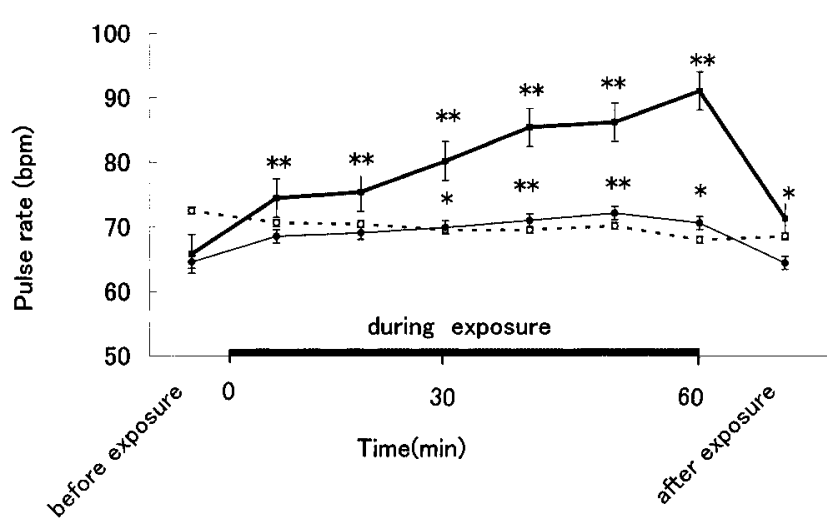

Fig. 3. Pulse rate changes of Tc ( $O), \mathrm{Tm}(O)$ and Th ( Values are means \pm SE. $* \mathrm{p}<0.05, * * \mathrm{p}<0.01$.

conditions, Tc, Tm and Th. Although pulse rate did not change during the experiment in the Tc condition, it increased significantly in the Tm and Th conditions (Fig. 3). In the Tc condition, sublingual temperature decreased significantly during the second half of the experiment. However, it increased significantly during the exposure in the Tm and Th conditions (Fig. 4).

Lipid concentrations during the experiment, adjusted for estimated plasma volume, are shown in Table 3. In the Tc condition, there was no significant difference in all values at $30 \mathrm{~min}$ and $60 \mathrm{~min}$ during exposure, and $30 \mathrm{~min}$ after exposure as compared to their pre-exposure concentrations ( $\mathrm{p}>0.05)$.

In the Tm condition, HDL-C increased significantly after exposure $(p<0.05)$, and FFA increased significantly at 60 $\min (\mathrm{p}<0.05)$ and after exposure $(\mathrm{p}<0.01)$ compared to preexposure concentration. Since TG concentrations were not in normal distribution in the Tm condition, they were analyzed 


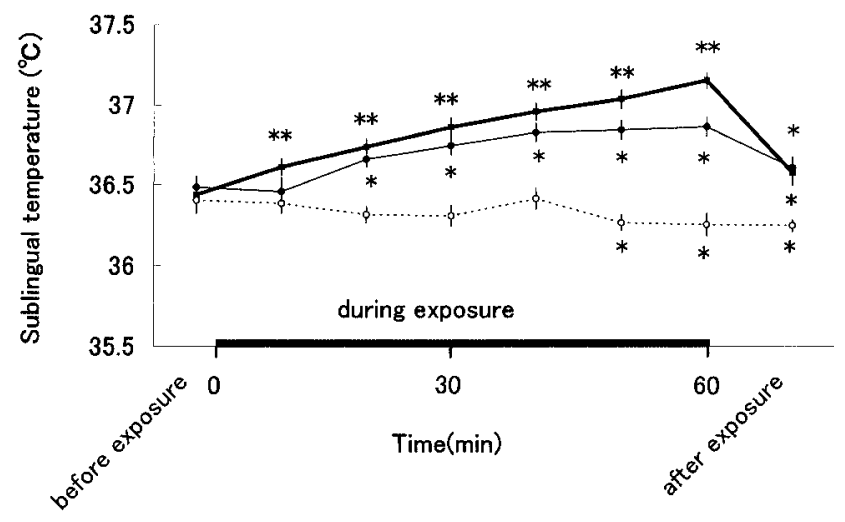

Fig. 4. Sublingual temperature changes of Tc $(\bigcirc), \operatorname{Tm}(\bigcirc)$ and Th ( $\square$ )

Values are means $\pm \mathrm{SE} . * \mathrm{p}<0.05, * * \mathrm{p}<0.01$

using the Kruskal-Wallis test, but the result showed that the changes in mean TG concentrations before, at $30 \mathrm{~min}$, at 60 min and after exposure were not significant $(\mathrm{p}>0.05)$.

In the Th condition, both TC and TG significantly decreased at $60 \mathrm{~min}$ and after exposure $(\mathrm{p}<0.05)$ compared to pre-exposure concentrations, while LDL-C decreased significantly at $60 \mathrm{~min}(\mathrm{p}<0.01)$, respectively.

There were significant changes in HDL-C and FFA in the Tm condition and TC, LDL-C and TG in the Th condition, however, no significant correlation was found between the individual's physical characteristics and the changes in these lipid concentrations.

\section{Discussion}

In this experiment TC and LDL-C decreased about $2 \%$ at $60 \mathrm{~min}$ in the Th condition compared to the pre-exposure concentrations. Several studies have reported that after an aerobic exercise TC and LDL-C concentrations were reduced by $3 \sim 5 \%$ and $4 \sim 8 \%$ respectively compared to their initial values $^{3-5)}$. Elevated body temperatures during heat exposure might be the cause of the changes in TC and LDL-C concentrations found in the present study. The reduction of serum cholesterol concentration under hot conditions might be related to the fact that the cell becomes thermal resistant through increasing the cholesterol concentration in the membrane ${ }^{18)}$. These cholesterols might be reduced because they are mobilized from serum into cellular membranes upon heat exposure. However, other study have reported opposite results, i.e., that lower cholesterol concentrations in the cellular membranes are associated with higher thermal resistance ${ }^{19)}$.

One reported experiment in vitro that cells take up more LDL-C through LDL-C receptors at high culture temperatures than at lower temperatures ${ }^{20)}$, implying that heat exposure might enhance LDL-C receptor gene expression and thus reduce LDL-C concentration in serum.

Other reports have indicated that activities of lipoprotein lipase and lecithin cholesterol acyltransferase increase after physical exercise, and these modifications might promote the release of TG from LDL, as a result HDL-C concentration

Table 3. The changes in serum lipid concentrations adjusted for changes in plasma volume

\begin{tabular}{|c|c|c|c|c|c|c|}
\hline & & & Before exposure & $30 \mathrm{~min}$ & $60 \mathrm{~min}$ & After exposure \\
\hline \multirow[t]{5}{*}{$\mathrm{Tc}$} & $\mathrm{TC}$ & $(\mathrm{mg} / \mathrm{dl})$ & $163.5 \pm 6.2$ & $163.1 \pm 6.8$ & $163.3 \pm 6.3$ & $162.5 \pm 6.4$ \\
\hline & LDL-C & $(\mathrm{mg} / \mathrm{dl})$ & $97.5 \pm 7.6$ & $97.6 \pm 7.9$ & $97.0 \pm 7.6$ & $96.6 \pm 7.7$ \\
\hline & HDL-C & $(\mathrm{mg} / \mathrm{dl})$ & $54.3 \pm 2.8$ & $54.2 \pm 2.7$ & $54.1 \pm 2.7$ & $53.8 \pm 2.6$ \\
\hline & TG & $(\mathrm{mg} / \mathrm{dl})$ & $77.5 \pm 8.9$ & $78.7 \pm 8.7$ & $76.2 \pm 8.0$ & $75.1 \pm 8.0$ \\
\hline & FFA & $(\mathrm{mEq} / \mathrm{l})$ & $0.59 \pm 0.10$ & $0.50 \pm 0.06$ & $0.54 \pm 0.07$ & $0.51 \pm 0.05$ \\
\hline \multirow[t]{5}{*}{$\mathrm{Tm}$} & $\mathrm{TC}$ & $(\mathrm{mg} / \mathrm{dl})$ & $153.3 \pm 5.7$ & $153.1 \pm 6.1$ & $151.8 \pm 6.0$ & $153.8 \pm 5.9$ \\
\hline & LDL-C & $(\mathrm{mg} / \mathrm{dl})$ & $88.3 \pm 6.3$ & $88.5 \pm 6.3$ & $88.0 \pm 6.5$ & $89.0 \pm 6.5$ \\
\hline & HDL-C & $(\mathrm{mg} / \mathrm{dl})$ & $55.2 \pm 2.9$ & $55.7 \pm 2.9$ & $55.3 \pm 2.8$ & $56.0 \pm 2.9^{* \#}$ \\
\hline & TG & $(\mathrm{mg} / \mathrm{dl})$ & $64.8 \pm 9.0$ & $65.0 \pm 8.9$ & $64.0 \pm 8.5$ & $66.0 \pm 8.8$ \\
\hline & FFA & $(\mathrm{mEq} / \mathrm{l})$ & $0.40 \pm 0.06$ & $0.47 \pm 0.06$ & $0.47 \pm 0.06^{*}$ & $0.50 \pm 0.06^{* * \#}$ \\
\hline \multirow[t]{5}{*}{ Th } & $\mathrm{TC}$ & $(\mathrm{mg} / \mathrm{dl})$ & $156.6 \pm 5.8$ & $155.2 \pm 5.7$ & $153.2 \pm 5.4^{*}$ & $154.0 \pm 5.8^{* \#}$ \\
\hline & LDL-C & $(\mathrm{mg} / \mathrm{dl})$ & $90.2 \pm 6.0$ & $89.9 \pm 5.9$ & $88.6 \pm 5.8 * *$ & $90.1 \pm 6.0^{\#}$ \\
\hline & HDL-C & $(\mathrm{mg} / \mathrm{dl})$ & $51.5 \pm 2.4$ & $51.9 \pm 2.3$ & $51.6 \pm 2.4$ & $52.3 \pm 2.3$ \\
\hline & TG & $(\mathrm{mg} / \mathrm{dl})$ & $94.5 \pm 13.2$ & $88.3 \pm 11.6$ & $83.7 \pm 11.1^{*}$ & $83.0 \pm 11.2^{\text {*\# }}$ \\
\hline & FFA & $(\mathrm{mEq} / \mathrm{l})$ & $0.47 \pm 0.05$ & $0.50 \pm 0.05$ & $0.48 \pm 0.05$ & $0.42 \pm 0.04^{\#}$ \\
\hline
\end{tabular}

TC: Total Cholesterol, LDL-C: Low-Density Lipoprotein Cholesterol, HDL-C: High-Density Lipoprotein Cholesterol, TG: Triglyceride, FFA: Free Fatty Acid, Values are expressed as means \pm SE, \#: Significant in ANOVA, $*(\mathrm{p}<0.05)$ and $* *(\mathrm{p}<0.01)$ : significantly different from value before exposure (Dunnett test). 
increases ${ }^{4,21,22)}$. In this study, the finding of increased HDL$\mathrm{C}$ after exposure indicated that the activities of these enzymes might be increased after heat exposure.

In the Th condition, TG concentration decreased $11 \%$ at 60 min compared with its pre-exposure level. Physical exercise has been reported to cause $1 \sim 6 \%$ reduction of $\mathrm{TG}^{3-5)}$. Serum TG concentration might have decreased because energy consumption might have increased due to the increase of metabolic rate caused by heat exposure. It has been reported that when subjects have low initial TG concentrations, TG values change little after exercise ${ }^{2-4)}$. Contrastingly, when initial TG concentrations are higher the change in TG value is greater ${ }^{5}$. In our experiment, TG showed the same pattern in the Th condition. There might be a possibility that hyperlipemic subjects have greater reduction of TG than normal subjects in hot environments.

Duane $\mathrm{O}$ et $a l .{ }^{23)}$ reported that serum FFA concentration increased along with the increasing core temperature during heat exposure and dehydration. In our study, FFA concentration increased $25 \%$ in the Tm condition after exposure but it did not change significantly in the Th condition. It is hypothesized that the supply of FFA might have exceeded its consumption in the Tm condition, while consumption might have increased in the Th condition.

MAP did not change significantly in the Tc, Tm and Th conditions, even though circulating plasma volume decreased under the three conditions. This might be due to the activation of the sympathetic nervous system and increased catecholamines secretions ${ }^{24)}$. It is generally accepted that the catecholamines are adipokinetic agents and increase the release of FFA from adipose tissue ${ }^{25,26}$. Duane also reported that the increase of FFA was suppressed when subjects were required to ingest a volume of water, estimated from a prior experiment, so as to exclude the effect of dehydration ${ }^{23)}$. To investigate the FFA concentration during heat exposure, it may be necessary to consider the effect of dehydration.

We did not find any significant correlation between changes in serum lipid concentrations and the subject's physical characteristics. Homogeneity in the physical factors of the subjects might be one explanation for the lack of correlation. If subjects with greater deviations in physical characteristics were involved, it might have been possible to reveal some level of correlation between the physical factors and changes in serum lipid concentrations.

The Pharmaceutical Society of Japan recommends the comfortable indoor environment to be about $25^{\circ} \mathrm{C}$ and $60 \%$ relative humidity, so we adopted this condition as the control temperature. Although the average sublingual temperatures decreased significantly in the Tc condition, the reduction in body temperature did not affect the serum lipid concentrations. It might have been better to use a warmer temperature as the control condition, so as to reduce heat loss in the subjects.

A few shortcomings of this study are: firstly, food intake pattern of the subjects was not taken into account. It has been well documented that food intake pattern is associated with serum lipid concentrations ${ }^{27-29)}$. If the adjustment for food intake prior to the experiment had been made in this experiment, any confounding effect of lipid intake could have been ruled out.

Secondly, individual heat acclimatization ability and physiological reactions to heat were not considered. All the subjects were exposed to the same conditions. The heat load and duration of heat exposure could have been determined according to the increase in core temperature, body weight loss and metabolic rate (such as oxygen consumption) in each subject ${ }^{30,31)}$.

WBGT Index is a simple expression of the degree of heat stress. It is closely related to the change in pulse and heart rates in hot conditions ${ }^{13)}$. The Japan Society for Occupational Health proposed that WBGT Index be used as a measure of the severity of occupational exposure to heat stress. In our experiment, WBGT Index in the Tm condition was similar to outdoor conditions during the summer $(31.5 \pm 0.1$ vs 29.5 \pm 0.4 ). In the Th condition, the WBGT Index was similar to conditions in steel and glass factories $(36.7 \pm 0.4$ vs $36.7 \pm$ $0.6)^{6,32,33)}$. There is a possibility that many workers are often exposed to similar conditions. Although there is a lot of evidence that heat affects many aspects of physiological functions, the general understanding of the effects of heat on serum lipids is still very limited due to the scarcity of reports. Lipids are essential for the body, however, morbidity related to the over intake or metabolic dysfunction of lipids still remains a severe health problems ${ }^{34}$. From the viewpoint of Preventive Medicine or Occupational Physiology, this study shows that heat exposure, while keeping the body at rest, affects serum lipid concentrations. Further investigations are needed to evaluate the effect of heat exposure on hyperlipemic subjects and the effects of longer heat exposure on serum lipid concentrations.

The results of this study suggest that the effect of heat exposure on blood lipid concentrations might be similar to that of physical exercise because heat exposure similarly reduced TC, LDL-C and TG while increased HDL-C and FFA.

\section{Acknowledgements}

We are indebted to the subjects for their dedication and 
cooperation. This study was supported by the Foundation for Total Health Promotion in Japan.

\section{References}

1) Hughes RA, Thorland WG, Housh TJ, Johnson GO (1990) The effect of exercise intensity on serum lipoprotein responses. J Sports Med Phys Fitness 30, 254-60.

2) Cullinane E, Lazarus B, Thompson PD, Saratelli A, Herbert PN (1981) Acute effects of a single exercise session on serum lipids in untrained men. Clin Chim Acta 109, 341-4.

3) Grandjean PW, Crouse SF, Rohack JJ (2000) Influence of cholesterol status on blood lipid and lipoprotein enzyme responses to aerobic exercise. J Appl Physiol 89, 472-80.

4) Kantor MA, Cullinane EM, Sady SP, Herbert PN, Thompson PD (1987) Exercise acutely increases high density lipoprotein-cholesterol and lipoprotein lipase activity in trained and untrained men. Metabolism 36, 188-92.

5) Crouse SF, O'Brien BC, Rohack JJ, Lowe RC, Green JS, Tolson H, Reed JL (1995) Changes in serum lipids and apolipoproteins after exercise in men with high cholesterol: influence of intensity. J Appl Physiol 79, 279-86.

6) Kurakake S, Nakaji S, Sugawara K, Okamura N, Oshita Y, Umeda T (1998) A study of the effects of physical load on umpires during the national high school baseball games-the effects of physical load on umpires at the Koshien stadium in a summer-heat environment. Nippon Eiseigaku Zasshi 52, 667-76.

7) al-Harthi SS, Karrar O, al-Mashhadani SA, Saddique AA (1990) Metabolite and hormonal profiles in heat stroke patients at Mecca pilgrimage. J Intern Med 228, 343-6.

8) William R, Keatinge WR, Coleshaw SR, Easton JC, Cotter F, Mattock MB, Chelliah R (1986) Increased platelet and red cell counts, blood viscosity, and plasma cholesterol levels during heat stress, and mortality from coronary and cerebral thrombosis. Am J Med 81, 795800.

9) Schmidt RF, Thews G (1987) Human physiology. 2nd ed., 690-1 Springer-Verlag Berlin Heidelberg, Germany.

10) Du Bois D, Du Bois EF (1916) Clinical calorimetry. Tenth paper: a formula to estimate the approximate area if height and weight be known. Arch Int Med 17, 86371.
11) Brozek J, Grande F, Anderson JT, Keys A (1963) Densitometoric analysis of body composition. Ann NY Sci 110, 113.

12) Suzuki R, Watanabe S, Hirai $Y$, Akiyama K, Nishide T, Matsushima Y, Murayama H, Ohshima H, Shinomiya M, Shirai K (1993) Abdominal wall fat index, estimated by ultrasonography, for assessment of the ratio of visceral fat to subcutaneous fat in the abdomen. Am J Med 95, 309-14.

13) George DC, Florence EC (1977) Patty's industrial hygene and toxicology 3rd ed., 956, John Wiley, New York.

14) Rodney R, Richard P (1992) Human physiology. 2nd ed., 657, Worth: Saunders College Pub.

15) Dill DB, Costill DL (1974) Calculation of percentage changes in volumes of blood, plasma, and red cells in dehydration. J Appl Physiol 37, 247-8.

16) Barbara HM (1997) Statistical methods for health care research. 3rd ed., 140 Lippincott, Philadelphia.

17) Beth DS, Robert GT (1997) Basic and clinical biostatistics. 2nd ed., 32 Medical Science International, Tokyo.

18) Cress AE, Gerner EW (1980) Cholesterol levels inversely reflect the thermal sensitivity of mammalian cells in culture. Nature 283, 677-9.

19) Anderson RL, Tao TW, Hahn GM (1988) Membrane lipids of B16 melanoma cells and heat-resistant variants. Int J Radiat Biol 54, 813-23.

20) Hoeg JM, Demosky SJ Jr, Schaefer EJ, Starzl TE, Brewer HB Jr. (1984) Characterization of hepatic low density lipoprotein binding and cholesterol metabolism in normal and homozygous familial hypercholesterolemic subjects. J Clin Invest 73, 429-36.

21) Dufaux B, Order U, Muller R, Hollmann W (1986) Delayed effects of prolonged exercise on serum lipoproteins. Metabolism 35, 105-9.

22) Taskinen MR, Nikkila EA (1981) High density lipoprotein subfractions in relation to lipoprotein lipase activity of tissues in man-evidence for reciprocal regulation of HDL2 and HDL3 levels by lipoprotein lipase. Clin Chim Acta 112, 325-32.

23) Duane O, Sparks KE, Turner CL (1976) The adipokinetic effect of hyperthermic stress in man. Eur J Appl Physiol Occup Physiol 35, 103-10.

24) Simmonds MA, Iverson LL (1970) Thermoregulation effects of environmental temperature on turnover of hypothalamic norepinephrine. Science 163, 473.

25) Ostman J, Efendic S (1970) Catecholamines and metabolism of human adipose tissue. II. Effect of 
isoprophylnoradrenaline and adrenergic blocking agents on lipolysis in human omental adipose tissue in vitro. Acta Med Scand 187, 471-6.

26) Havel RJ (1968) The autonomic nervous system and intermediary carbohydrate and fat metabolism. Anesthesiology 29, 702-13.

27) Twisk JW, Kemper HC, van Mechelen W, Post GB (1997) Which lifestyle parameters discriminate highfrom low-risk participants for coronary heart disease risk factors. Longitudinal analysis covering adolescence and young adulthood. J Cardiovasc Risk 4, 393-400.

28) Nakanishi N, Nakamura K, Ichikawa S, Suzuki K, Tatara K (1999) Relationship between lifestyle and serum lipid and lipoprotein levels in middle-aged Japanese men. Eur J Epidemiol 15, 341-8.

29) Ellison RC, Myers RH, Zhang Y, Djousse L, Knox S, Williams RR, Province MA(1999) Effects of similarities in lifestyle habits on familial aggregation of high density lipoprotein and low density lipoprotein cholesterol: the NHLBI Family Heart Study. Am J Epidemiol 150, 910-
8.

30) Armstrong CG, Kenney WL (1993) Effects of age and acclimation on responses to passive heat exposure. $\mathrm{J}$ Appl Physiol 75, 2162-7.

31) Buono MJ, Heaney JH, Canine KM (1998) Acclimation to humid heat lowers resting core temperature. Am J Physiol 274, R1295-9.

32) oopat P, Vanwonterghem K, Intaranont K (1998) An assessment of workload in the Thai steel industry. Appl Ergon 29, 267-71.

33) Srivastava A, Kumar R, Joseph E, Kumar A (2000) Heat exposure study in the workplace in a glass manufacturing unit in India. Ann Occup Hyg 44, 44953.

34) Kitamura A, Iso H, Iida M, Naito Y, Sato S, Jacobs DR, Nakamura M, Shimamoto T, Komachi Y. (2002) Trends in the incidence of coronary heart disease and stroke and the prevalence of cardiovascular risk factors among Japanese men from 1963 to 1994. Am J Med 112, 104-9. 